\title{
Abstract \\ Impact of pulse oximetry screening on the detection of duct dependent Congenital Heart Diseases
}

\author{
Bandara S*, Irugalbandara S, Mahanama L, Pethiyagoda K, Muniweera A, Herath J, Gamage S, \\ Muhandiram D, Shankini C \\ ${ }^{1}$ Teaching Hospital Peradeniya, Sri Lanka
}

\begin{abstract}
Background

Cardio vascular malformations are the commonest type of congenital malformations, but most are not detected by routine neonatal examination. Approximately 1-1.8 babies per 1000 live births have a duct dependent circulation, with a persistent ductus arteriosus being necessary for survival. These babies are at particular risk due to the trend towards early discharge from postnatal wards. Critical congenital heart defect (CCHD) is life threatening and requires intervention in infancy. However, CCHD is not always detected prenatally or upon examination in the post natal wards. As a result, some infants with CCHD are discharged from the postnatal wards to home, where they quickly decompensate.

\section{Methods}

Prospective study was done over ten weeks duration in the postnatal wards in Teaching Hospital Peradeniya. The preductal and postductal oxygen saturation $\left(\mathrm{SpO}_{2}\right)$ of 1450 clinically healthy term newborns was measured by using pulse oximeter before they were discharged from the wards by a medical officer.

\section{Results}

Out of 1450 babies, the screening was positive in seven babies. The 2D Echocardiogram was done by a Consultant Paediatric Cardiologist. All seven of them confirmed to be suffered from a CHD. Among them, there was one Critical CHD which needed immediate surgical intervention and six other CHDs where four of them needed medical management for Persistent Pulmonary Hypertension as well. The sensitivity and the specificity of this screening test was $100 \%$.

\section{Conclusion}

As the using of pulse oximetry is a low cost, painless and non-invasive procedure which can be done within minutes it is an effective method that can be used in our set up to screen duct dependent CHDs.
\end{abstract}

Key words: Duct dependent congenital heart diseases; Persistent ductus arteriosus; Screening; Preductal and Post ductal saturation

Copyright: (C) 2015 Bandara S et al. This is an open access article distributed under the Creative Commons Attribution License, which permits unrestricted use, distribution, and reproduction in any medium, provided the original work is properly cited.

* Correspondence : msskbandara@yahoo.com

Cite this abstract as: Bandara S, Irugalbandara S, Mahanama L, Pethiyagoda K, Muniweera A, Herath J, Gamage S, Muhandiram D, Shankini C. Impact of pulse oximetry screening on the detection of duct dependent Congenital Heart Diseases. Anuradhapura Medical Journal 2015;9 (2Supp):S22.

DOI:http://dx.doi.org/10.4038/amj.v9i2Supp.7571 


\section{Submit your next Manuscript to Anuradhapura}

Submit your manuscript at

http://amj.sljol.info/ 